\title{
Associations of Sleep Quality and Frailty among the Older Adults with Chronic Disease in China: The Mediation Effect of Psychological Distress
}

\author{
Peipei Fu ${ }^{1}$, Chengchao Zhou ${ }^{2, * \mathbb{C}}$ and Qingyue Meng ${ }^{3}$ \\ 1 School of Health Care Management, Cheeloo College of Medicine, Shandong University, \\ NHC Key Laboratory of Health Economics and Policy Research, Jinan 250012, China; fupeipei@sdu.edu.cn \\ 2 School of Public Health, Cheeloo College of Medicine, NHC Key Lab of Health Economics and Policy \\ Research, Shandong University, Jinan 250012, China \\ 3 China Center for Health Development Studies, Peking University, Beijing 100191, China; \\ qmeng@bjmu.edu.cn \\ * Correspondence: zhouchengchao@sdu.edu.cn; Tel.: +86-531-8838-1567; Fax: +86-531-8838-2553
}

Received: 17 June 2020; Accepted: 19 July 2020; Published: 20 July 2020

\begin{abstract}
Frailty affects the elderly and leads to adverse health outcomes. Preliminary evaluations have suggested that sleep quality and psychological distress are predictors of frailty among older adults. However, the mechanisms by which sleep quality affect frailty had not been fully addressed in the previous research. This study aimed to explore the mediation effect of psychological distress on the association between sleep quality and frailty among the elderly with chronic diseases in rural China. A total of 2346 old adults were included in the analysis. Frailty status was measured by Fried Phenotype criteria. Sleep quality was assessed by Pittsburgh Sleep Quality Index (PSQI), and psychological distress was examined by Kessler Psychological Distress Scale (K10). Ordinal logistic regressions were performed to assess the relationships between sleep quality and frailty. Mediation test was also conducted by bootstrap method. The prevalence rate of frailty among the elderly with chronic diseases was $21 \%$ in rural China. Compared with the elder of robust status, respondents identified as having frailty have lower SES, less vigorous physical activity, and worse self-reported health status. Poor sleep quality was a significant predictor of frailty with mediators (OR $=1.44,95 \% \mathrm{CI}=1.19-1.76$ ). Mediation analysis suggested that psychological distress mediated $41.81 \%$ of total effect between sleep quality and frailty. This study indicated that poor sleep quality was significantly related to frailty, and psychological was a mediator of this association. However, we could not investigate causal relationships between variables since this was one cross-sectional study. These findings suggested that an early detection of sleep problems and also psychological disorders should be taken to prevent frailty among the rural older adults in China.
\end{abstract}

Keywords: frailty; sleep quality; psychological distress; mediation effect

\section{Introduction}

Frailty in older adults is one complicated condition accompanied with aging and characterized with progressive decline in physiological reserves and resistance to stressors, which are related to increased morbidity and mortality [1,2]. Numerous evidences have linked frailty to negative health, such as disability, hospitalization, higher mortality rates, and threaten quality of life of older adults $[3,4]$. Previous studies indicate that chronic diseases are positively associated with the onset of frailty [5-7]. A study in Singapore demonstrate that frailty prevalence in older adults with diabetes is twice of that in general population [8]. In addition, frail individuals with chronic disease are demonstrated to have higher risk of mortality [9]. Thus, frailty among the individuals with chronic disease requires 
more attention. Moreover, studies suggest frailty is reversible and can be treated and delayed by interventions, such as health promotion, nutrition, physical, and social support [10-13]. Therefore, with the rapid growth of aging population, special attentions should be paid on exploring risk factors and preventing frailty among the older adults with chronic diseases.

Previous studies have explored risk factors associated with frailty. A systematic review suggests that there is a positive association between sleep quality and frailty [14]. On study reports, long sleep durance $(\geq 10 \mathrm{~h})$ is associated with higher risk of pre-frail and frail status [15]. In China, around 37.75\% of the older adults living in urban areas are suffering from poor sleep quality, such as sleep disorder, sleep disturbance, and insomnia [16,17]. A cross-sectional study performed in urban China report similar results that poor sleep quality and long sleep duration increased the prevalence of pre-frailty and frailty [18]. Given the concerning relationship between poor sleep quality and frailty, questions still remain unanswered regarding the underlying pathways between sleep quality and frailty among older adults in rural China.

Findings from empirical studies suggest one potential mediating role of psychological distress. Previous studies in rural China suggest that abnormal sleep is associated with anxiety and depressive symptoms $[19,20]$. In particular, sleep duration is one predictor of anxiety, and insufficient sleep is a causal factor in depression [21,22]. Additionally, insomnia will increase risks of mental illness [23,24]. It has also been demonstrated that certain forms of psychological disorder including depression and suicidal ideation are associated with an increased risk of frailty $[25,26]$. Therefore, we hypothesize that psychological distress may mediate the association of sleep quality and frailty among the elderly with chronic diseases.

To the best of our knowledge, literatures on the underlying mechanisms to explain how sleep quality is associated with frailty are limited and should be further examined, in particular with mediating effects. A recent research demonstrated that mood regulation on depression and anxiety is a potential mediator of physical activity on sleep quality [27]. Furthermore, the frail older adults with chronic diseases living in rural areas deserve more attention since they have a lack of health knowledge and access to health-care management, which makes them more vulnerable. The objectives of this study are: (1) to assess the association between sleep quality and frailty among older adults with chronic diseases in rural China and (2) to explore the mediation effect of psychological distress between sleep quality and frailty.

\section{Materials and Methods}

\subsection{Study Design and Sample}

Data were drawn from a cross-sectional study conducted in Shandong Province, the second largest province in China. The survey was conducted in 2019 as the first wave of the Longevity and Aging Cohort Study, which aims to investigate health status of the elderly living in rural areas of China. Multistage random sampling was used to recruit senior citizens above 60 years old and living at rural areas. To do so, three cities were first chosen representing different economic development levels and location within the province. Within each city, five townships were randomly chosen and four villages in each township were finally chosen as our study sites. Face-to-face interview were conducted among respondents, and then a brief physical examination was done by our training investigators.

The criteria for inclusion in this study were as follows: (1) aged 60 years or above; (2) older individual with at least one chronic disease including hypertension, diabetes, dementia, waist and leg pain, chronic gastritis, stroke, and cancer. To obtain accurate data, we exclude respondents who could not answer the questionnaire independently. All of the completed questionnaires were carefully checked by the supervisors after the interview each day. In total, 3600 individuals were recruited and 3243 completed the whole survey, with a response rate of $90.05 \%$. Of the respondents, 896 respondents were excluded for without chronic conditions and one respondent was excluded from our analysis due 
to the lack of data in psychological distress survey. Finally, 2346 respondents were included in the final statistical analysis.

\subsection{Frailty Status Measurements}

Frailty status was determined based on the Fried Phenotype criteria which assess frailty in five aspects: unintentional weight loss, exhaustion, physical activity, walk time, and grip strength $[28,29]$. Frailty was identified as one meet three and more criterions, pre-frailty was determined as individual meet one and two of the criteria, and robust was defined as one meet none of the characteristics. In this study, five criterions were measured as follows (see Appendix A Table A1 for cut-off points):

(1) Unintentional weight loss. This criterion was defined as the unintentional weight loss more than $5 \%$ over last year by asking questions: "what was your weight last year" and "Did you lose weight intentionally?"

(2) Exhaustion. Defined as self-reported "feel exhausted to do everything" or "I could not go on with my life" more than 3 times a week will receive a score of 1 .

(3) Weakness. Defined as grip strength smaller than the lowest $20 \%$ by gender and Body Mass Index (BMI). The grip strength was assessed by dynamometer for three times and took average of the measurements.

(4) Slowness. Slowness was defined by the speed of walking $4.6 \mathrm{~m}$ adjusting gender and height.

(5) Low physical activity. Defined according to International Physical Activity Questionnaire-short version [30,31]. Each activity was assigned a metabolic equivalent (MET) energetic cost value. The total Kcals of activity for last seven days was calculated by total minutes of physical activities times MET score adjusting gender.

\subsection{Sleep Quality}

Sleep quality was assessed by Pittsburgh Sleep Quality Index (PSQI) [32]. This scale consisted 19 self-reported questions in seven dimensions including sleep duration, time to fall asleep, sleep disturbance, sleep efficiency, daytime dysfunction, medications to sleep, etc. [33]. The total score range is $0-20$ and the higher of the PSQI score represents worse sleep quality. In this study, the cut off value was set at 7 , and individual's PSQI score greater than 7 represented poor sleep quality [34].

\subsection{Psychological Distress}

Psychological health status was examined by Kessler Psychological Distress Scale (K10) which was used to assess psychological distress and has been widely applied in screening psychological health for elders [35,36]. This questionnaire contains 10 items with five-point scale to measure frequency of symptoms associated with nonspecific mental health conditions, such as anxiety and stress in the previous month by asking questions: "Do you often feel nervous?", "Do you often feel helpless?", "Do you often fell depressed?", “Do you often feel worthless?", etc. The total score range is 0-50 and higher score were classified as poor psychological health status. As previous study suggested, psychological status was classified into four categories based on K10 score: no psychological distress (10-15), mild psychological distress (16-21), moderate psychological distress (22-29), and severe psychological distress (30-50) [37].

\subsection{Statistic Analysis}

The data were analyzed by STATA 14.2 (Stata Corp; College Station, TA, USA). Descriptive statistical analysis with Chi-square test was performed to test variances of demographic characteristics by different frailty groups. Ordinal logistic regressions were used to investigate associations between frailty and sleep quality, and effects mediated by psychological distress. We performed the test proposed by Baron and Kenny [38]. Specifically, three regression models with control variables were conducted as shown in Figure 1: firstly, ordinal logistic regression was conducted to test the association between sleep quality and frailty; secondly, ordinal logistic regression was performed to 
exam association between psychological disorder on sleep quality; finally, ordinal logistic regression was conducted to explore relationship between sleep quality and frailty with psychological disorder included in the model. The mediation effect test model was conducted as follows:

$$
\begin{gathered}
Y=c X+e_{1} \\
M=a X+e_{2} \\
Y=c^{\prime} X+b M+e_{3}
\end{gathered}
$$

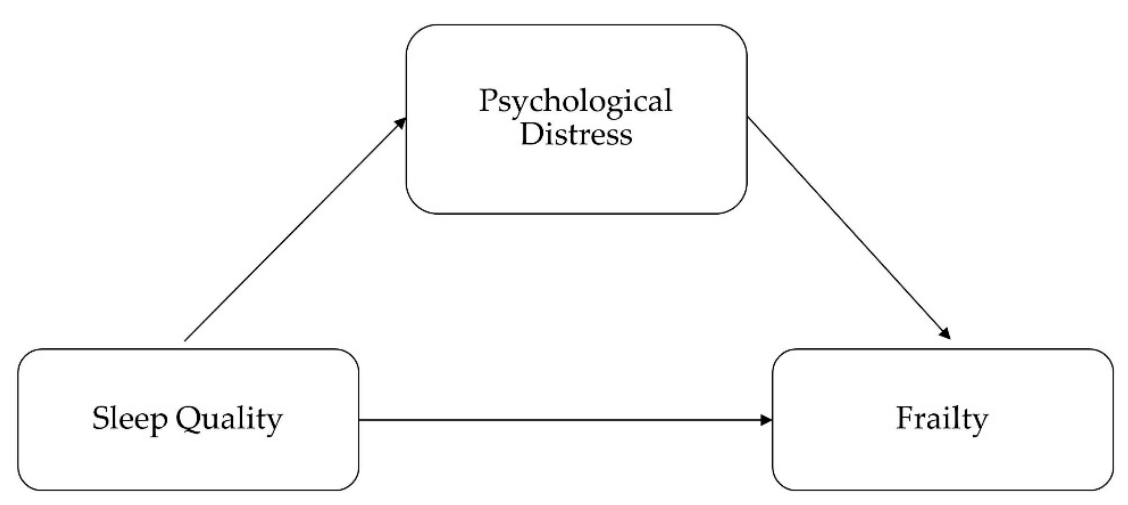

Figure 1. Diagram of the mediation model.

The mediation effects were tested by bootstrap method [39,40]. Odds ratio (OR) values with $95 \%$ confident intervals (CI) were also presented. The ordinal logistic regressions were adjusted for social demographic characteristics with gender, age, education, occupation, marital status, and household income. Variables including activity, alcohol intake, smoking, BMI index, and self-reported health status were also regarded as covariates in the statistical analysis. In addition, we conducted a sensitivity analysis on psychological distress and sleep quality, and on sleep quality and frailty with psychological distress as a mediator using categorical and continuous K10 scores, respectively.

\subsection{Ethical Consideration}

This study protocol was approved by the Ethical Committee of Shandong University School of Public Health (No. 20,181,228). All respondents were fully informed with written consent for participation prior to the face-to-face interview.

\section{Results}

The socio-demographic characteristics of the respondents with Chi-square test results were presented in Table 1 . The percentage of respondents identified as robust, pre-frailty, and frailty were $15 \%, 64 \%$, and $21 \%$, respectively. About $65 \%$ of the participants were female, and average age of frailty elders was higher than elders without frailty. Nearly half of the participants had not attended school. More than half of the participants with poor self-reported health status suffered from frailty. There was no significant difference in BMI $(p=0.671)$ and smoking habits $(p=0.506)$ among frail older adults. Furthermore, significant differences existed among respondents with different levels of household income, physical activity, and self-reported health status. 
Table 1. Demographic characteristics of older people by category of frailty status in rural Shandong, China $(n=2346)$.

\begin{tabular}{|c|c|c|c|c|c|}
\hline \multirow{2}{*}{ Characteristics } & \multirow{2}{*}{ All N (\%) } & Robust & Pre-Frailty & Frailty & \multirow{3}{*}{$p$-Value } \\
\hline & & $n(\%)$ & $n(\%)$ & $n(\%)$ & \\
\hline Total & $2346(100)$ & 342 (15) & $1504(64)$ & $500(21)$ & \\
\hline \multicolumn{6}{|l|}{ Gender } \\
\hline Male & $820(35)$ & $109(32)$ & $550(37)$ & $161(32)$ & \multirow[t]{2}{*}{0.090} \\
\hline Female & $1526(65)$ & $233(68)$ & $954(63)$ & $339(68)$ & \\
\hline \multicolumn{5}{|l|}{ Age (years) } & \multirow[b]{2}{*}{$<0.001$} \\
\hline Mean \pm SD & 70.15 (6.05) & $68.19(5.03)$ & $70.08(6.00)$ & $71.70(6.41)$ & \\
\hline \multicolumn{5}{|l|}{ Education } & \multirow{4}{*}{$<0.001$} \\
\hline Illiteracy & $963(41)$ & $117(34)$ & $627(42)$ & $219(44)$ & \\
\hline Junior school & $948(40)$ & $136(40)$ & $600(40)$ & $212(42)$ & \\
\hline Senior school+ & $435(19)$ & $89(26)$ & $277(18)$ & $69(14)$ & \\
\hline \multicolumn{5}{|l|}{ Occupation } & \multirow{3}{*}{$<0.001$} \\
\hline Unemployed & $1026(44)$ & $99(29)$ & $632(42)$ & $295(59)$ & \\
\hline Farmers & $1320(56)$ & $243(71)$ & $872(58)$ & $205(41)$ & \\
\hline \multicolumn{5}{|l|}{ Marital Status } & \multirow{3}{*}{0.209} \\
\hline Married & $1737(74)$ & $266(78)$ & $1108(74)$ & $363(73)$ & \\
\hline Other & $609(26)$ & $76(22)$ & $396(26)$ & $137(27)$ & \\
\hline \multicolumn{5}{|c|}{ Household income/year } & \multirow{4}{*}{$<0.001$} \\
\hline$<7 \mathrm{~K}$ & 787 (33) & $65(19)$ & $513(34)$ & $209(42)$ & \\
\hline $7-15 \mathrm{~K}$ & $657(28)$ & $114(33)$ & $404(27)$ & $139(28)$ & \\
\hline$>15 \mathrm{~K}$ & $902(39)$ & $163(48)$ & $587(39)$ & $152(30)$ & \\
\hline \multicolumn{5}{|l|}{ Activity } & \multirow{3}{*}{$<0.001$} \\
\hline Moderate & $1166(49)$ & $134(39)$ & $697(46)$ & $335(67)$ & \\
\hline Vigorous & $1180(51)$ & $208(61)$ & $807(54)$ & $165(33)$ & \\
\hline \multicolumn{5}{|l|}{ Drinking } & \multirow{4}{*}{$<0.001$} \\
\hline None & $1708(72)$ & $247(72)$ & $1067(71)$ & $394(79)$ & \\
\hline Ever & $178(8)$ & $24(7)$ & $122(8)$ & $32(6)$ & \\
\hline Current & $460(20)$ & $71(21)$ & $315(21)$ & $74(15)$ & \\
\hline \multicolumn{5}{|l|}{ Smoking } & \multirow{4}{*}{0.506} \\
\hline None & $1652(70)$ & $249(73)$ & $1048(70)$ & $355(71)$ & \\
\hline Ever & $262(11)$ & $41(12)$ & $170(11)$ & $51(10)$ & \\
\hline Current & $432(19)$ & $52(15)$ & $286(19)$ & $94(19)$ & \\
\hline \multicolumn{5}{|l|}{ BMI } & \multirow{2}{*}{0.671} \\
\hline Mean \pm SD & $24.72(4.05)$ & $24.62(3.46)$ & $24.78(4.08)$ & $24.63(4.31)$ & \\
\hline \multicolumn{5}{|c|}{ Self-reported Health Status } & \multirow[t]{4}{*}{$<0.001$} \\
\hline Poor & $786(33)$ & $53(15)$ & $455(30)$ & $278(56)$ & \\
\hline Medium & $740(32)$ & $109(32)$ & $499(33)$ & $132(26)$ & \\
\hline Good & $820(35)$ & $180(53)$ & $550(37)$ & 90 (18) & \\
\hline
\end{tabular}

Notes: Senior school+: represents senior school and above.

\subsection{Effects of Sleep Quality on Psychological Distress}

Table 2 reported the estimation results of three models to test the mediating effect of psychological distress on the association between sleep quality and frailty. Specifically, model 2 presented odds ratios of the associations between sleep quality and psychological distress. The estimation results in model 2 suggested that compared with those with high sleep quality (PSQI $<7$ ), older adults with poor sleep quality (PSQI $\geq 7$ ) were more likely to be of psychological distress $(\mathrm{OR}=3.48, \mathrm{CI}=2.89$, $4.18, p$-value $<0.001)$, after controlling for the potential confounding variables. 
Table 2. The mediating effect of psychological distress on the association between sleep quality and frailty among elders with chronic diseases $(n=2346)$.

\begin{tabular}{lcccccc}
\hline \multirow{2}{*}{ Variables } & \multicolumn{2}{c}{$\begin{array}{c}\text { Model 1 } \\
\text { Frailty }\end{array}$} & \multicolumn{2}{c}{$\begin{array}{c}\text { Model 2 } \\
\text { Psychological Distress }\end{array}$} & \multicolumn{2}{c}{$\begin{array}{c}\text { Model 3 } \\
\text { Frailty }\end{array}$} \\
\cline { 2 - 7 } & OR & $\mathbf{9 5 \% ~ C I ~}$ & OR & $\mathbf{9 5 \% ~ C I ~}$ & OR & $\mathbf{9 5 \% ~ C I ~}$ \\
\hline Sleep quality & - & - & - & - & - & - \\
PSQI $<7$ (ref.) & - & - & - & - & - & - \\
PSQI $\geq 7$ & $1.84^{* * *}$ & $(1.53,2.23)$ & $3.48^{* * *}$ & $(2.89,4.18)$ & $1.44^{* * *}$ & $(1.19,1.76)$ \\
Psychological distress & & - & - & - & - & - \\
No (ref.) & - & - & - & - & - & - \\
Mild & - & - & - & - & $1.63^{* * *}$ & $(1.29,2.05)$ \\
Moderate & & - & - & - & $2.34^{* * *}$ & $(1.81,3.02)$ \\
Severe & - & - & - & - & $4.43^{* * *}$ & $(3.15,6.22)$ \\
\hline
\end{tabular}

Notes: OR represents the odds ratio, and $95 \%$ CI represents $95 \%$ confidence intervals. The above models adjusted for socio-demographic variables, drinking, smoking, BMI, chronic diseases, and self-reported health status variables. $* * * p<0.001$.

\subsection{Effects of Sleep Quality and Psychological Distress on Frailty}

Model 3 tested associations between sleep quality, psychological distress, and frailty. The analysis results indicated that worse sleep quality $(\mathrm{OR}=1.44, \mathrm{CI}=1.19,1.76, p$-value $<0.001)$ was significantly associated with frailty development (robust, pre-frailty, and frailty). Similar relationship was observed from psychological distress on frail older adults with chronic diseases, as $\mathrm{OR}=1.63, \mathrm{CI}=1.29,2.05$, $p$-value $<0.001$ for mild, $\mathrm{OR}=2.34, \mathrm{CI}=1.81,3.02, p$-value $<0.001$ for moderate, and $\mathrm{OR}=4.43$, $\mathrm{CI}=3.15,6.22, p$-value $<0.001$ for severe. Model 1 examined relationships between sleep quality and frailty without psychological distress; the result indicated that the odds of having pre-frailty and frailty will increase by a factor of 1.84 for individuals who had poor sleep quality $(\mathrm{OR}=1.84, \mathrm{CI}=1.53,2.23$, $p$-value $<0.001$ ). Additionally, the sensitivity analysis including the categorical and continuous K10 scores reported a similar association between sleep quality and psychological distress, and between sleep and frailty (Tables S1 and S2).

\subsection{Mediation Effects of Psychological Distress on Frailty}

The mediation effects by psychological distress were tested by bootstrap, and results indicated psychological distress partially mediated $41.81 \%$ of the total effects of sleep quality on frailty. The odds ratio of PSQI in Table 2 decreased from $1.84(\mathrm{CI}=1.53,2.23)$ to $1.44(\mathrm{CI}=1.19,1.76)$ as psychological distress included in the full model. This indicated that the effect of sleep quality on frailty was partially mediated by psychological distress. Participants who had poor sleep quality and mild to severe psychological distress had a more sever frailty. All three statistic regression models were adjusted for socio-demographic variables, health behavior, and health status variables.

\section{Discussion}

In this cross-sectional study, after adjustment for a variety of confounders, we have identified that both sleep quality and psychological distress were significantly associated with frailty status. Our study also suggested that sleep quality was highly associated with psychological distress. Therefore, we revealed that psychological distress mediated partially of the relationship between sleep quality and frailty. Furthermore, our study found the prevalence rate of frailty in the elderly with chronic diseases (21\%) was higher than among general Chinese elders (18\%) [41]. Additionally, the present study suggested that older female had a higher prevalence of frailty $(19.22 \%)$ than that of male $(15.74 \%)$, which has been widely found in previous studies [19,42]. One meta-analysis indicated that the pooled prevalence of frailty was $8 \%$ in males and $11 \%$ in females [43]. Therefore, the frail elders with chronic diseases should be addressed for policy makers. 
Consistent with previous research, our study also found that poor sleep quality was associated with frailty $[44,45]$. We found that $75.6 \%$ of older adults who had poor sleep quality were accompanied with pre-frail and frail status. Previous studies also indicated sex difference existed in the relationship between poor sleep quality and frailty; specifically, women were associated with higher risk of frailty than men $[46,47]$. Similarly, this study revealed that the prevalence of poor sleep quality of women was higher than men, but sex difference was not significant between sleep quality and frailty.

In line with previous research, our results showed that sleep quality was associated with psychological distress and individuals with poor sleep quality were significantly related to severe psychological distress [48]. Our study recognized that the prevalence rate of poor sleep was significantly higher in individuals with psychological distress (80.4\%) than that without psychological distress (19.6\%) among older adults. This extended previous finding that sleep quality negatively correlated with individual's mood, since sleep problems threaten quality of life and associated with mood in older adults [49]. Our results could be explained by the fact that poor sleep quality, such as trouble in falling asleep and short sleep duration, will impair mood and increase anxiety with daytime fatigue, therefore causing psychological disorders [50,51].

One potential mechanism was psychological disorder explained how sleep quality impact frailty was through inadequate activity. Previous literatures suggested that poor sleep quality would result in depression and decreased physical activity, increasing the risk of negative health conditions [52,53]. In particular, a longitudinal study suggested that long sleepers were characterized with inadequate activity and muscle strength, and slow walking speed which contributing to frailty [54]. Such findings were supported in our study as participants engage in vigorous activity associated with lower frailty.

Another mechanism that poor sleep quality lead to frailty among older adults with chronic diseases was explained by oxidative stress. Literature had proved that oxidative stress was a predictor of age-related diseases including cardiovascular diseases, Alzheimer's diseases, and other neurodegenerative disorders [55], and lead to musculoskeletal damage which in turn results in frailty [56]. In addition, oxidative stress contributed to sleep disorder and sleep disorder with depression were confounding determinants of fatigue [57]. Ultimately, senior residents with pre-frail and frail status were more likely to suffer from chronic comorbidities, which were triggered by oxidative stress [58].

Based on the results and interpretation, we have verified the hypothesis that poor sleep quality contributes to frailty and partially mediated by psychological distress in rural China. Therefore, we recommend health policies aiming to prevent elders from falling into frailty and enhance healthy aging. First, joint policy avocation should be addressed to strengthen the early diagnosis and treatment of rural elders with sleep problems and psychological disorders. Moreover, healthy aging could be enhanced by promoting healthy behaviors including participating in moderate to vigorous physical exercise regularly to improve physical capacity and prevent frailty in elders. Accordingly, policies should be initiated on the development and maintaining of healthy behaviors, especially encouraging engagement in regular physical activities to reduce chronic diseases and improve sleep quality. Additionally, psychological health of the elderly in rural China should be highlighted through strategic policy interventions such as social support from family and community. Public environment also needs to be improved to upgrade overall living conditions for rural residents.

Our study has several limitations. We could not investigate causal relationships between variables since this was one cross-sectional study. Due to resource constraints, this study was conducted in a single province, which may limit the generalizability of the study results to other areas in China. In addition, variables values collected such as health status and recall of sleep habits in previous month were self-reported; therefore, bias might exist in the values. Future research should be conducted to explore other underling mechanisms to explain how sleep quality affect frailty among older adults with chronic diseases so as to provide evidence for policy interventions. 


\section{Conclusions}

This study was the first to explore mediation effect of psychological distress on associations between sleep quality and frailty among the elderly with chronic diseases in rural China. We found poor sleep quality was significantly associated with frailty, and psychological distress was a mediator of this association. These findings implied that an early detection of sleep problems and also psychological disorders by regular monitoring and timely interventions, such as improving social support from community or treatment would be helpful for preventing frailty among the rural older adults in China.

Supplementary Materials: The following are available online at http://www.mdpi.com/1660-4601/17/14/5240/s1, Table S1: Model estimation using categorical K10 vs. continuous K10, Table S2: Model estimation using categorical K10 vs. continuous K10.

Author Contributions: Conceptualization, C.Z. and P.F.; writing—original draft preparation, P.F.; writing一review and editing, C.Z. and Q.M. All authors have read and agreed to the published version of the manuscript.

Funding: This research was funded by the National Foundation of China (71774104; 71473152; 71974117), the China Medical Board (16-257), a Cheeloo Youth Scholar Grant, the foundation of Shandong University (IFYT18032, IFYT1810; 2012DX006), and NHC Key laboratory of Health Economics and Policy Research (NHC-HEPR2019002). The funding bodies had no role in the design, data collection, analysis, interpretation of the data, and writing of this article.

Acknowledgments: We thank the officials of health agencies, all participants and staffs at the study sites for their contribution.

Conflicts of Interest: The authors declare no conflict of interest.

\section{Appendix A}

Table A1. Cut-off points for frailty measurements.

\begin{tabular}{|c|c|c|}
\hline Measures & Cut-Off Points for $F_{1}$ & ailty \\
\hline Weakness & 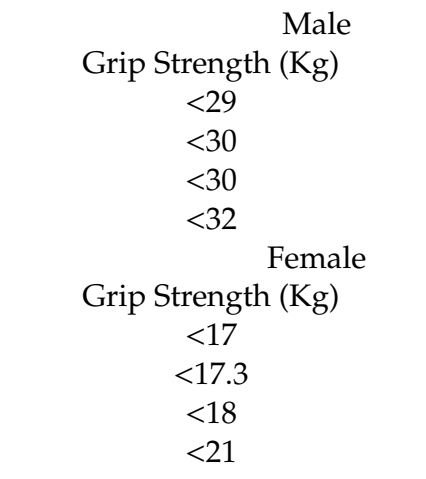 & $\begin{array}{c}\text { BMI } \\
\leq 24 \\
24.1-26 \\
26.1-28 \\
>28 \\
\\
\text { BMI } \\
\leq 23 \\
23.1-26 \\
26.1-29 \\
>29\end{array}$ \\
\hline Slowness & 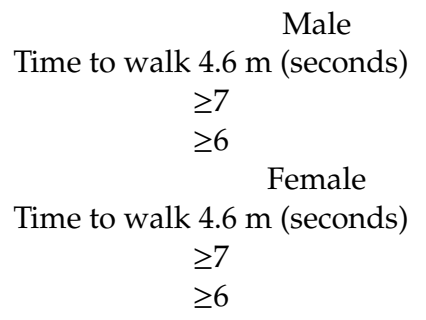 & $\begin{array}{l}\text { Height }(\mathrm{cm}) \\
\quad \leq 173 \\
>173 \\
\\
\text { Height }(\mathrm{cm}) \\
\quad \leq 159 \\
>159\end{array}$ \\
\hline Low physical Activity & $\begin{array}{l}\text { Male } \\
\text { Total Kcals (per week) } \\
<383 \\
\text { Female } \\
\text { Total Kcals (per week) } \\
<270\end{array}$ & - \\
\hline
\end{tabular}




\section{References}

1. Villacampa-Fernandez, P.; Navarro-Pardo, E.; Tarin, J.J.; Cano, A. Frailty and multimorbidity: Two related yet different concepts. Maturitas 2017, 95, 31-35. [CrossRef]

2. Clegg, A.; Young, J.; Iliffe, S.; Rikkert, M.O.; Rockwood, K. Frailty in elderly people. Lancet 2013, 381, $752-762$. [CrossRef]

3. Santos-Eggimann, B.; Sirven, N. Screening for frailty: Older populations and older individuals. Public Health Rev. 2016, 37, 7. [CrossRef] [PubMed]

4. Buckinx, F.; Rolland, Y.; Reginster, J.Y.; Ricour, C.; Petermans, J.; Bruyere, O. Burden of frailty in the elderly population: Perspectives for a public health challenge. Arch. Public Health 2015, 73, 19. [CrossRef] [PubMed]

5. Sahle, B.W.; Chen, W.; Melaku, Y.A.; Akombi, B.J.; Rawal, L.B.; Renzaho, A.M.N. Association of psychosocial factors with risk of chronic diseases: A nationwide longitudinal study. Am. J. Prev. Med. 2020, 58, E39-E50. [CrossRef] [PubMed]

6. Renne, I.; Gobbens, R.J.J. Effects of frailty and chronic diseases on quality of life in Dutch community-dwelling older adults: A cross-sectional study. Clin. Interv. Aging 2018, 13, 325-334. [CrossRef] [PubMed]

7. Amaral, C.D.; Amaral, T.L.M.; Monteiro, G.T.R.; De Vasconcellos, M.T.L.; Portela, M.C. Factors associated with low handgrip strength in older people: Data of the study of chronic diseases (Edoc-I). BMC Public Health 2020, 20, 395.

8. $\quad$ Merchant, R.A.; Chen, M.Z.; Tan, L.W.L.; Lim, Y.D.; Ho, H.K.; Van Dam, R.M. Singapore healthy older people everyday (HOPE) study: Prevalence of frailty and associated factors in older adults. J. Am. Med. Dir. Assoc. 2017, 18, 734.e9-734.e14. [CrossRef]

9. Adabag, S.; Vo, T.N.; Langsetmo, L.; Schousboe, J.T.; Cawthon, P.M.; Stone, K.L.; Shikany, J.M.; Taylor, B.C.; Ensrud, K.E. Frailty as a risk factor for cardiovascular versus noncardiovascular mortality in older men: Results from the mros sleep (outcomes of sleep disorders in older men) study. J. Am. Heart Assoc. Cardiovasc. Cerebrovasc. Dis. 2018, 7, 1785. [CrossRef]

10. Avgerinou, C.; Gardner, B.; Kharicha, K.; Frost, R.; Liljas, A.; Elaswarapu, R.; Manthorpe, J.; Drennan, V.M.; Goodman, C.; Iliffe, S.; et al. Health promotion for mild frailty based on behaviour change: Perceptions of older people and service providers. Health Soc. Care Community 2019, 27, 1333-1343. [CrossRef]

11. Ng, T.P.; Feng, L.; Nyunt, M.S.Z.; Feng, L.; Niti, M.; Tan, B.Y.; Chan, G.; Khoo, S.A.; Chan, S.M.; Yap, P.; et al. Nutritional, physical, cognitive, and combination interventions and frailty reversal among older adults: A randomized controlled trial. Am. J. Med. 2015, 128, 1225-1236.e1. [CrossRef] [PubMed]

12. Zhang, Y.; Xu, X.J.; Lian, T.Y.; Huang, L.F.; Zeng, J.M.; Liang, D.M.; Yin, M.J.; Huang, J.X.; Xiu, L.C.; Yu, Z.W.; et al. Development of frailty subtypes and their associated risk factors among the community-dwelling elderly population. Aging-US 2020, 12, 1128-1140. [CrossRef] [PubMed]

13. Hsieh, T.-J.; Su, S.-C.; Chen, C.-W.; Kang, Y.-W.; Hu, M.-H.; Hsu, L.-L.; Wu, S.-Y.; Chen, L.; Chang, H.-Y.; Chuang, S.-Y.; et al. Individualized home-based exercise and nutrition interventions improve frailty in older adults: A randomized controlled trial. Int. J. Behav. Nutr. Phys. Act. 2019, 16, 119. [CrossRef] [PubMed]

14. Wai, J.L.T.; Yu, D.S.F. The relationship between sleep-wake disturbances and frailty among older adults: A systematic review. J. Adv. Nurs. 2020, 76, 96-108. [CrossRef] [PubMed]

15. Baniak, L.M.; Yang, K.; Choi, J.; Chasens, E.R. Long sleep duration is associated with increased frailty risk in older community-dwelling adults. J. Aging Health 2020, 32, 42-51. [CrossRef] [PubMed]

16. Wang, Y.M.; Chen, H.G.; Song, M.; Xu, S.J.; Yu, L.L.; Wang, L.; Wang, R.; Shi, L.; He, J.; Huang, Y.Q.; et al. Prevalence of insomnia and its risk factors in older individuals: A community-based study in four cities of Hebei Province, China. Sleep Med. 2016, 19, 116-122. [CrossRef]

17. Wang, P.; Song, L.; Wang, K.L.; Han, X.L.; Cong, L.; Wang, Y.X.; Zhang, L.; Yan, Z.R.; Tang, S.; Du, Y.F. Prevalence and associated factors of poor sleep quality among Chinese older adults living in a rural area: A population-based study. Aging Clin. Exp. Res. 2020, 32, 125-131. [CrossRef]

18. Sun, X.H.; Ma, T.; Yao, S.; Chen, Z.K.; Xu, W.D.; Jiang, X.Y.; Wang, X.F. Associations of sleep quality and sleep duration with frailty and pre-frailty in an elderly population Rugao longevity and ageing study. BMC Geriatr. 2020, 20, 9. [CrossRef] 
19. Jiang, J.J.; Li, Y.Q.; Mao, Z.X.; Wang, F.; Huo, W.Q.; Liu, R.H.; Zhang, H.Q.; Tian, Z.Y.; Liu, X.T.; Zhang, X.; et al. Abnormal night sleep duration and poor sleep quality are independently and combinedly associated with elevated depressive symptoms in Chinese rural adults: Henan rural cohort. Sleep Med. 2020, 70, 71-78. [CrossRef]

20. Zhou, L.; Zhang, H.Q.; Luo, Z.C.; Liu, X.T.; Yang, L.Y.; Hua, H.Y.; Wang, Y.; Wang, C.J.; Wang, F. Abnormal night sleep duration and inappropriate sleep initiation time are associated with elevated anxiety symptoms in Chinese rural adults: The henan rural cohort. Psychiatry Res. 2020, 291, 113232. [CrossRef]

21. Meerlo, P.; Havekes, R.; Steiger, A. Chronically restricted or disrupted sleep as a causal factor in the development of depression. In Sleep, Neuronal Plasticity and Brain Function; Meerlo, P., Benca, R.M., Abel, T., Eds.; Springer Berlin Heidelberg: Berlin/Heidelberg, Germany, 2015; pp. 459-481.

22. De Sousa, D.E.; De Carli, M.N.; Fernandes, R.C.; Trindade, D.B.; Laviano, A.; Pichard, C.; Pimentel, G.D. Are depression and anxiety disorders associated with adductor pollicis muscle thickness, sleep duration, and protein intake in cancer patients? Exp. Gerontol. 2020, 130, 5. [CrossRef] [PubMed]

23. Biddle, D.J.; Kelly, P.J.; Hermens, D.F.; Glozier, N. The association of insomnia with future mental illness: Is it just residual symptoms? Sleep Health 2018, 4, 352-359. [CrossRef] [PubMed]

24. Kay, D.B.; Dombrovski, A.Y.; Buysse, D.J.; Reynolds, C.F.; Begley, A.; Szanto, K. Insomnia is associated with suicide attempt in middle-aged and older adults with depression. Int. Psychogeriatr. 2016, 28, 613-619. [CrossRef] [PubMed]

25. Brown, P.J.; Roose, S.P.; O’Boyle, K.R.; Ciarleglio, A.; Maas, B.; Igwe, K.C.; Chung, S.; Gomez, S.; Naqvi, M.; Brickman, A.M.; et al. Frailty and its correlates in adults with late life depression. Am. J. Geriatr. Psychiatr. 2020, 28, 145-154. [CrossRef]

26. Bickford, D.; Morin, R.T.; Woodworth, C.; Verduzco, E.; Khan, M.; Burns, E.; Nelson, J.C.; Mackin, R.S. The relationship of frailty and disability with suicidal ideation in late life depression. Aging Ment. Health 2019. [CrossRef]

27. Mccrae, C.S.; Mcnamara, J.P.H.; Rowe, M.A.; Dzierzewski, J.M.; Dirk, J.; Marsiske, M.; Craggs, J.G. Sleep and affect in older adults: Using multilevel modeling to examine daily associations. J. Sleep Res. 2008, 17, 42-53. [CrossRef]

28. Fried, L.P.; Tangen, C.M.; Walston, J.; Newman, A.B.; Hirsch, C.; Gottdiener, J.; Seeman, T.; Tracy, R.; Kop, W.J.; Burke, G.; et al. Frailty in older adults: Evidence for a phenotype. J. Gerontol. A Biol. Sci. Med. Sci. 2001, 56, M146-M156. [CrossRef]

29. Ward, R.E.; Orkaby, A.R.; Chen, J.Y.; Hshieh, T.T.; Driver, J.A.; Gaziano, J.M.; Djousse, L. Association between diet quality and frailty prevalence in the physicians' health study. J. Am. Geriatr. Soc. 2020, 68, 770-776. [CrossRef]

30. Ningning, Q.; Keji, L. Study on the reliability and validity of international physical activity questionnaire (Chinese Version, IPAQ). Chin. J. Epidemiol. 2004, 25, 265-268.

31. Craig, C.L.; Marshall, A.L.; Sjostrom, M.; Bauman, A.E.; Booth, M.L.; Ainsworth, B.E.; Pratt, M.; Ekelund, U.; Yngve, A.; Sallis, J.F.; et al. International physical activity questionnaire: 12-country reliability and validity. Med. Sci. Sports Exerc. 2003, 35, 1381-1395. [CrossRef]

32. Buysse, D.J.; Reynolds, C.F.; Monk, T.H.; Berman, S.R.; Kupfer, D.J. The pittsburgh sleep quality index-a new instrument for psychiatric practice and research. Psychiatry Res. 1989, 28, 193-213. [CrossRef]

33. Del Brutto, O.H.; Mera, R.M.; Sedler, M.J.; Zambrano, M.; Nieves, J.L.; Cagino, K.; Fanning, K.D.; Milla-Martinez, M.F.; Castillo, P.R. The effect of age in the association between frailty and poor sleep? quality: A population-based study in community-dwellers (the atahualpa project). J. Am. Med Dir. Assoc. 2016, 17, 269-271. [CrossRef] [PubMed]

34. Gao, Y.Q.; Pan, B.C.; Sun, W.; Wu, H.; Wang, L. Anxiety symptoms among Chinese nurses and the associated factors: A cross sectional study. BMC Psychiatry 2012, 12, 141. [CrossRef] [PubMed]

35. Kessler, R.; Barker, P.; Colpe, L.; Epstein, J.; Zaslavsky, A. Short screening scales to monitor population prevalences and trends in non-specific psychological distress. Psychol. Med. 2002, 32, 959-976. [CrossRef]

36. Anderson, T.M.; Sunderland, M.; Andrews, G.; Titov, N.; Dear, B.F.; Sachdev, P.S. The 10-item Kessler psychological distress scale (K10) as a screening instrument in older individuals. Am. J. Geriatr. Psychiatry 2013, 21, 596-606. [CrossRef] [PubMed]

37. Zhou, C.C.; Jiang-Jiang, H.E.; Ling-Zhong, X.U. First application of Kessler 10 scale to measuring mental health status of the aged in China. Chin. J. Clin. Psychol. 2009, 17, 761-763. 
38. Baron, R.M.; Kenny, D.A. The moderator-mediator variable distinction in social psychological research: Conceptual, strategic, and statistical considerations. J. Personal. Soc. Psychol. 1986, 51, 1173-1182. [CrossRef]

39. Preacher, K.J.; Hayes, A.F. Asymptotic and resampling strategies for assessing and comparing indirect effects in multiple mediator models. Behav. Res. Methods 2008, 40, 879-891. [CrossRef]

40. Kim, H.J.; Park, S.; Park, S.H.; Heo, Y.W.; Chang, B.S.; Lee, C.K.; Yeom, J.S. The significance of frailty in the relationship between socioeconomic status and health-related quality of life in the Korean community-dwelling elderly population: Mediation analysis with bootstrapping. Qual. Life Res. 2017, 26, 3323-3330. [CrossRef]

41. Jiao, J.; Wang, Y.; Zhu, C.; Li, F.; Zhu, M.; Wen, X.; Jin, J.; Wang, H.; Lv, D.; Zhao, S.; et al. Prevalence and associated factors for frailty among elder patients in China: A multicentre cross-sectional study. BMC Geriatr. 2020, 20, 100. [CrossRef]

42. Ye, B.; Chen, H.; Huang, L.M.; Ruan, Y.; Qi, S.G.; Guo, Y.F.; Huang, Z.Z.; Sun, S.Y.; Chen, X.Q.; Shi, Y.; et al. Changes in frailty among community- dwelling chinese older adults and its predictors: Evidence from a two-year longitudinal study. BMC Geriatr. 2020, 20, 130. [CrossRef] [PubMed]

43. He, B.; Ma, Y.; Wang, C.; Jiang, M.; Geng, C.; Chang, X.; Ma, B.; Han, L. Prevalence and risk factors for frailty among community-dwelling older people in china: A systematic review and meta-analysis. J. Nutr. Health Aging 2019, 23, 442-450. [CrossRef] [PubMed]

44. Tuna, F.; Ustundag, A.; Can, H.B.; Tuna, H. Rapid geriatric assessment, physical activity, and sleep quality in adults aged more than 65 years: A preliminary study. J. Nutr. Health Aging 2019, 23, 617-622. [CrossRef] [PubMed]

45. Campanini, M.Z.; Mesas, A.E.; Carnicero-Carreno, J.A.; Rodriguez-Artalejo, F.; Lopez-Garcia, E. Duration and quality of sleep and risk of physical function impairment and disability in older adults: Results from the enrica and elsa cohorts. Aging Dis. 2019, 10, 557-569. [CrossRef]

46. Kang, I.; Kim, S.; Kim, B.S.; Yoo, J.; Kim, M.; Won, C.W. Sleep latency in men and sleep duration in women can be frailty markers in community-dwelling older adults: The Korean Frailty and Aging Cohort Study (KFACS). J. Nutr. Health Aging 2019, 23, 63-67. [CrossRef]

47. Moreno-Tamayo, K.; Manrique-Espinoza, B.; Rosas-Carrasco, O.; Perez-Moreno, A.; Salinas-Rodriguez, A. Sleep complaints are associated with frailty in Mexican older adults in a rural setting. Geriatr. Gerontol. Int. 2017, 17, 2573-2578. [CrossRef]

48. Bernert, R.A.; Joiner, T.E., Jr.; Cukrowicz, K.C.; Schmidt, N.B.; Krakow, B. Suicidality and sleep disturbances. Sleep 2005, 28, 1135-1141. [CrossRef]

49. Schnittger, R.I.B.; Walsh, C.D.; Casey, A.M.; Wherton, J.P.; McHugh, J.E.; Lawlor, B.A. Psychological distress as a key component of psychosocial functioning in community-dwelling older people. Aging Ment. Health 2012, 16, 199-207. [CrossRef]

50. Seaton, V.A.; Narcisse, M.R.; Subica, A.M.; Long, C.R.; Matthews, E.E.; McElfish, P.A. Sleep quality partially mediates the association between type 2 diabetes and psychological distress in native hawaiian and pacific islander adults in the united states: Analysis of the 2014 national health interview survey. Asian Am. J. Psychol. 2019, 10, 258-267. [CrossRef]

51. De Rooij, A.; Van Der Leeden, M.; Roorda, L.D.; Rinkema, M.; Beuving, W.; Dekker, J. Factors associated with sleep quality in patients with chronic widespread pain attending multidisciplinary treatment. Pain Pract. 2020, 20, 471-479. [CrossRef]

52. Grov, E.K.; Fosså, S.D.; Dahl, A.A. Insomnia in elderly cancer survivors-A population-based controlled study of associations with lifestyle, morbidity, and psychosocial factors. Results from the Health Survey of North-Trøndelag County (HUNT-2). Support. Care Cancer 2011, 19, 1319-1326. [CrossRef] [PubMed]

53. Kumar, S.; Wong, P.S.; Hasan, S.S.; Kairuz, T. The relationship between sleep quality, inappropriate medication use and frailty among older adults in aged care homes in Malaysia. PLoS ONE 2019, 14, e0224122. [CrossRef] [PubMed]

54. Morgan, K.; Hartescu, I. Sleep duration and all-cause mortality: Links to physical activity and prefrailty in a 27-year follow up of older adults in the UK. Sleep Med. 2019, 54, 231-237. [CrossRef] [PubMed]

55. Liguori, I.; Russo, G.; Curcio, F.; Bulli, G.; Aran, L.; Della-Morte, D.; Gargiulo, G.; Testa, G.; Cacciatore, F.; Bonaduce, D.; et al. Oxidative stress, aging, and diseases. Clin. Interv. Aging 2018, 13, 757-772. [CrossRef]

56. Derbre, F.; Gratas-Delamarche, A.; Gomez-Cabrera, M.C.; Vina, J. Inactivity-induced oxidative stress: A central role in age-related sarcopenia? Eur. J. Sport Sci. 2014, 14, S98-S108. [CrossRef] 
57. Norheim, K.B.; Jonsson, G.; Omdal, R. Biological mechanisms of chronic fatigue. Rheumatology 2011, 50, 1009-1018. [CrossRef]

58. Patel, R.S.; Ghasemzadeh, N.; Eapen, D.J.; Sher, S.; Arshad, S.; Ko, Y.A.; Veledar, E.; Samady, H.; Zafari, A.M.; Sperling, L.; et al. Novel biomarker of oxidative stress is associated with risk of death in patients with coronary artery disease. Circulation 2016, 133, 361-369. [CrossRef]

(C) 2020 by the authors. Licensee MDPI, Basel, Switzerland. This article is an open access article distributed under the terms and conditions of the Creative Commons Attribution (CC BY) license (http://creativecommons.org/licenses/by/4.0/). 